\title{
Interprofessional versus monoprofessional case-based learning in childhood cancer and the effect on healthcare professionals' knowledge and attitudes: study protocol for a randomised trial
}

Martha Krogh Topperzer ${ }^{1 *}$ (D), Marianne Hoffmann², Hanne Bækgaard Larsen', Susanne Rosthøj3 , Jacob Nersting ${ }^{1}$, Louise Ingerslev Roug ${ }^{1}$, Peter Pontoppidan ${ }^{2}$, Liv Andrés-Jensen ${ }^{1}$, Birgitte Lausen ${ }^{2}$, Kjeld Schmiegelow ${ }^{1,2}$ and Jette Led Sørensen ${ }^{4}$

\begin{abstract}
Background: Interprofessional education in childhood cancer is a multifaceted field involving multiple healthcare professionals with general and specialised knowledge and skills. Complex treatment, care and rehabilitation require continuous professional development and maintenance of healthcare professionals' competencies in their field of expertise. However, limited knowledge exists in comparing interprofessional and monoprofessional education. Only a few randomised studies have evaluated the effectiveness and efficiency of interprofessional education.

The objective of this single-centre, investigator-initiated cluster randomised trial is to study the effect of interprofessional versus monoprofessional case-based learning on healthcare professionals' knowledge of gastrointestinal side effects and attitudes towards team collaboration.

Methods: This study will randomise healthcare professionals to participate in either the experimental interprofessional group or the control monoprofessional group of case-based learning. The topic of the case-based intervention will be gastrointestinal side effects, one of six categories identified in a three-round Scandinavian Delphi study as relevant for interprofessional education in childhood cancer.

The primary outcome is the self-reported questionnaire Assessment of Interprofessional Team Collaboration Scale. Secondary outcomes are measured by the self-reported questionnaires Readiness for Interprofessional Learning Scale Questionnaire, Safety Attitudes Questionnaire, and knowledge will be evaluated using a multiple-choice quiz. Participants will receive the self-reported questionnaires about 2 weeks before and 1 month after the intervention. On the day of the intervention, participants will answer a multiple-choice quiz before and after the case-based learning. Linear mixed models will be used to compare differences between the two groups in mean scores postintervention, (Continued on next page)
\end{abstract}

\footnotetext{
* Correspondence: martha.krogh.topperzer@regionh.dk

'Paediatric Oncology Research Laboratory, Department of Paediatrics and

Adolescent Medicine, Rigshospitalet, University of Copenhagen, Blegdamsvej

9, 2100 Copenhagen, Denmark

Full list of author information is available at the end of the article
}

(C) The Author(s). 2020 Open Access This article is licensed under a Creative Commons Attribution 4.0 International License, which permits use, sharing, adaptation, distribution and reproduction in any medium or format, as long as you give appropriate credit to the original author(s) and the source, provide a link to the Creative Commons licence, and indicate if changes were made. The images or other third party material in this article are included in the article's Creative Commons licence, unless indicated otherwise in a credit line to the material. If material is not included in the article's Creative Commons licence and your intended use is not permitted by statutory regulation or exceeds the permitted use, you will need to obtain permission directly from the copyright holder. To view a copy of this licence, visit http://creativecommons.org/licenses/by/4.0/. The Creative Commons Public Domain Dedication waiver (http://creativecommons.org/publicdomain/zero/1.0/) applies to the data made available in this article, unless otherwise stated in a credit line to the data. 
(Continued from previous page)
adjusting for preintervention scores.

Discussion: This study will provide insight into the differences between interprofessional and monoprofessional casebased learning and how it affects healthcare professionals' knowledge of gastrointestinal side effects and attitudes towards team collaboration.

Trial registration: The intervention was registered at Clinical Trials.gov: NCT04204109 on December 102,019 and with the National Committee on Health Research Ethics: H-19087506 December 112,019 and the Danish Data Protection Agency: P-2019-637 October 152,019.

Keywords: Interprofessional education, Continuing professional education, Childhood cancer, Team collaboration

\section{Background}

Interprofessional education in childhood cancer is a multifaceted field involving multiple healthcare professionals with general and specific knowledge and skills. Complex treatment, care and rehabilitation require continuous professional development and maintenance of healthcare professionals' competencies in their field of expertise to provide children and adolescents with cancer and their families the best possible treatment and care [1].

There has been a shift in the treatment paradigm in childhood cancer from cure towards normality and interprofessional collaboration in childhood cancer research has contributed to this [2, 3]. Four out of five children with cancer will survive [4], but half of all children with acute lymphoblastic leukaemia are still affected by at least one of 14 severe toxic, treatmentrelated side effects [5]. Moreover, the burden of mortality in childhood cancer survivors is high and continues in adulthood [6].

To continuously ensure and strengthen high-quality treatment and care, interprofessional education must be strategically planned based on a curriculum involving all relevant healthcare professionals and specific learning outcomes [7]. This necessitates a curriculum framework comprising problem identification, needs assessment, aims and objectives, educational strategies, implementation, assessment and evaluation, and feedback [7].

In a scoping review, we described a lack of wellstructured and evaluated interprofessional education programmes [8]. Postgraduate education at the department of paediatric oncology, Rigshospitalet, University of Copenhagen is organised monoprofessionally, with no formal curriculum for ensuring delivery of safe, highquality interprofessional healthcare to this group of children, adolescents and their families.

In a three-round Scandinavian Delphi study to establish consensus on learning objectives for an interprofessional education programme in childhood cancer [9], 30 designated experts from 12 out of 14 childhood cancer departments in Denmark, Norway and Sweden identified 168 learning objectives in six categories: 1) acute life- threatening situations, 2) gastrointestinal side effects, 3) pain, 4) palliation, 5) play and activity, and 6) prescription and administration of medicine.

The learning objectives in the second category: gastrointestinal side effects will inform the case and the multiple-choice quiz that will be applied in this trial (see supplemental material for learning objectives).

This trial will focus solely on the second category as gastrointestinal side effects are frequent and potentially severe clinical problems in childhood cancer that involve multiple healthcare professionals.

The objective of this trial is to study the effect of interprofessional versus monoprofessional case-based learning (CBL) on healthcare professionals' knowledge of gastrointestinal side effects and attitudes towards team collaboration.

The hypothesis is that interprofessional case-based learning (ICBL) will improve healthcare professionals' knowledge of gastrointestinal side effects and attitudes towards team collaboration.

\section{Methods \\ Trial design}

In this randomised controlled trial, the experimental group are interprofessional groups receiving $\mathrm{CBL}$ on children and adolescents with cancer and gastrointestinal side effects. The control groups are monoprofessional groups of either nurses or doctors. See Fig. 1 for a flowchart with an overview of the phases in the randomised controlled trial. The two groups will be taught using the same case.

\section{Setting and eligibility criteria}

This randomised controlled trial will take place at Rigshospitalet, University of Copenhagen and include eligible healthcare professionals from four departments: inpatient department for children and adolescents with cancer; inpatient department for transplantation of children and adolescents with cancer; and two outpatient departments for children and adolescents with cancer (Fig. 2 provides an overview of eligible participants). Professionals employed elsewhere includes priests, pedagogues (pre- 


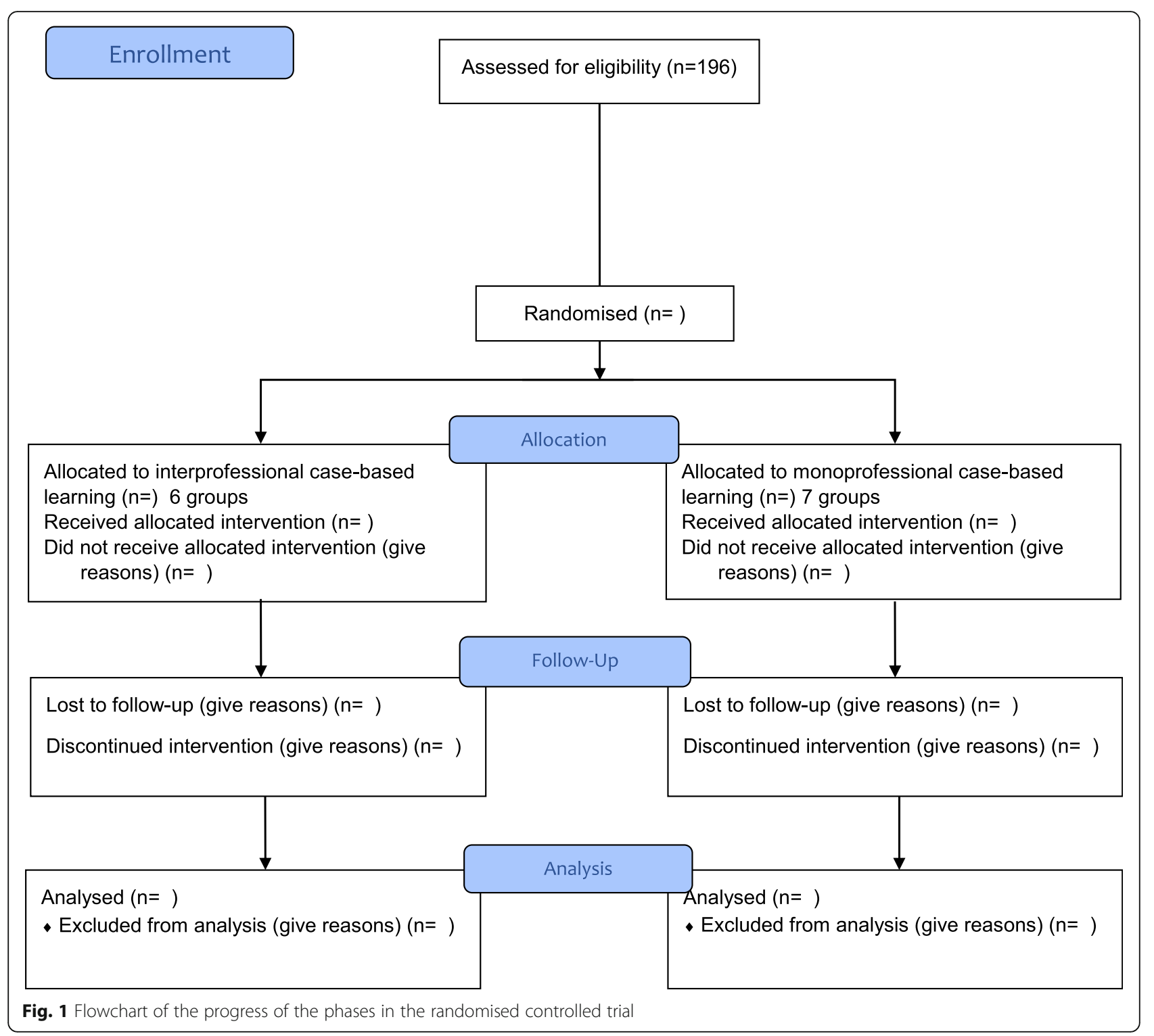

school teachers), physiotherapists, social workers, teachers, occupational therapists and dieticians.

\section{Exclusion criteria}

Staff managers and staff involved in organising the study will be excluded from the intervention.

\section{Participant withdrawal}

Participants will be informed by the principal investigator that they can withdraw their consent and discontinue their participation at any time. If any data has already been obtained, participants will be asked to give permission to include their data.

\section{Recruitment}

All eligible healthcare professionals will be informed individually or in groups about the trial (for information material, please contact the corresponding author). Participants will be encouraged by the head of departments to participate in the programme.

\section{Details of the intervention}

The intervention design is based on the CBL literature [10-12] and the research team's didactic experience. To answer the study aims of increasing the healthcare professionals' knowledge of gastrointestinal side effects and attitude toward team collaboration, we developed a case based on national guidelines, standard operating procedures and the identified learning objectives from the 


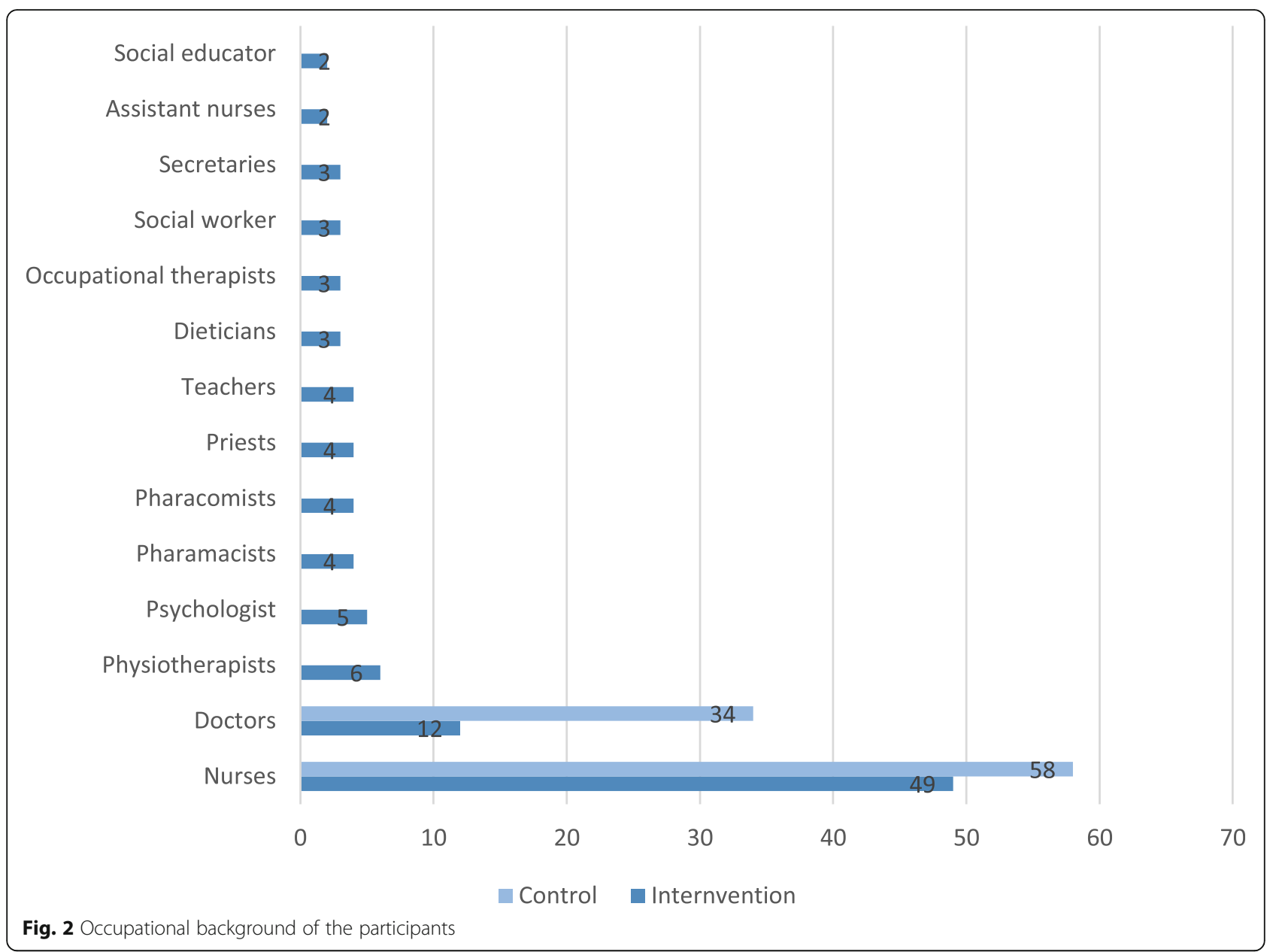

Delphi study [9]. The CBL method originating from the Harvard Business School engages participants in a structured manner towards uncovering decisions process' and actions patterns [13]. The CBL method is ideal for healthcare professionals as discussions are part of the complex clinical decision-making process in healthcare $[14,15]$. CBL sessions will not be used to teach traditionally from facilitator to healthcare professional. Rather, the didactic approach includes facilitators encouraging participants to think aloud, explain their rationales, observations, considerations and suggestions. The facilitators will guide the participants' thought process through the structure of clinical decision-making by posing questions, eliciting opinions and stimulating a discussion, so the participants themselves explore their knowledge and attitudes [13]. For examples of learning objectives applied, see Table 1.

At the core of the case method will be a real patient situation based on anonymised data containing no identifiable traits. The case will be open to interpretation as it is imperative to give as many possible alternative interpretations to what caused the problem and potential solutions (see Table 2 for exempt from the case).
A board or flip-overs will lead and synchronise the work of the group in a structured manner (see Table 3 Board illustration). The columns on the board stem from heuristic clinical problem solving (definition of problems, gathering of facts, hypothesis, hypothesis testing and feedback).

The intervention consists of three and a half hours of CBL. Table 4 present a tentative programme. The intervention will be arranged at least 3 months in advance on a specific day in the healthcare professionals' work schedule and take place during regular working hours. Participants will receive their regular salary. Participation

Table 1 Example of learning objectives for the CBL session

In relation to gastrointestinal toxicities and side effects, $\underline{\text { ALL }}$ PROFESSIONALS (teachers, pedagogues, social workers,

physiotherapists, all medical doctors, nurses and other professionals affiliated with your clinic) should be able to:

1. Identify one's own professional limitations and ask for help

2. Identify need for communication with the nurse and/or doctor in charge of patient 
Table 2 Exempt from case

\begin{abstract}
Day 1 Monday
Larry is 14 years ord. His has a high risk Acute Lymphatic Leukaemia (ALL) and follows the treatment protocol of ALL2gether. Today, Larry is admitted to the day hospital for his day 22 chemotherapy, vincristine as a bolus and Daunorubicin over $1 \mathrm{~h}$.

While the nurse administers the chemo to Larry's central iv line, she asks how he is feeling. Larry tells her that his tummy hurts.

Larry's mom tells the nurse that she does not think Larry has had stools in 2 days. He does not want to talk about it. Larry's mom also says that Larry's legs hurt and that he does not have the strength to come out off bed at home. All he does is lie in the sofa and watch his Ipad. When he does come out of bed, he drags his legs behind him. This morning it took his mom3 $\mathrm{h}$ to get out of bed.
\end{abstract}

is voluntary; however, participation is endorsed and planned in coordination with staff management.

The research team designing the case represents the two largest professional groups in childhood cancer: doctors and nurses. The facilitators will be supervised and supported by the researchers (MKT, JLS) on how to build an atmosphere conducive to facilitating CBL in an interprofessional setting [14].

The participants in the experimental group will be randomised into six interprofessional teams. The computer-generated allocation sequence will be designed to ensure an adequate composition of health professionals resembling authentic clinical teams of 10-18 people. For example, four nurses, two doctors, one physiotherapist, one priest, one teacher, one social worker and one pharmacist.

The participants in the control group will be randomised into four monoprofessional groups comprised exclusively of nurses and three groups exclusively of doctors (See Fig. 2).

Two weeks to one month before the CBL session, the participants will receive an email with a link to the three questionnaires (AITCS, RIPLS and SAQ) generated in the secure web application REDCap [16]. A follow-up questionnaire will be sent to the participants 1-3 months after the intervention with a link to the same three questionnaires (see Fig. 3 for Timepoints of measurements).

An MCQ will test the participants' knowledge before and after the CBL (see an example of MCQ item in Table 5). It will consist of one best answer format with three options will be developed for this trial based on guidelines for designing and developing questionnaires
$[17,18]$. The items in the multiple-choice quiz will be based on content in national guidelines. The national guidelines will be distributed to the participants before the CBL session by email as course material and will be available online [19].

\section{Pilot testing}

The case and the multiple-choice quiz will be pilot tested on a group of healthcare professionals that resemble the interprofessional group. The facilitators of the CBL will be two doctors and two nurses who work with education, supervision and introduction of experienced new staff from the paediatric oncology department. The multiple-choice quiz will be face- and content validated [18].

The participants will be asked whether they participated in any other childhood cancer CBL interventions between enrolment in the trial and answering the final questionnaires.

For exploratory analysis, the CBL sessions will be audiorecorded, and field notes will be taken focusing on the perceived dynamics and interactions in the room [20].

\section{Outcomes}

For primary and secondary outcomes, we will use selfreported questionnaires, using a five-point Likert Scale. All scales are professionally translated and validated for a Danish context [21-23].

\section{Primary outcome}

Assessment of Interprofessional Team Collaboration Scale (AITCS) is a self-reported assessment of team collaboration for healthcare professionals [24]. We chose this instrument as it is one of the rare instruments that measure interprofessional team collaboration in qualified healthcare professionals. The Danish version is from 2011 and consists of three subscales; 1) Partnership/ shared decision making (19 items), 2) Collaboration (11 items), 3) Coordination (7 items) [21, 22]. The items are distributed on a 5 -point Likert scale, $5=$ always, $4=$ most of the time, 3 =occasionally, $2=$ rarely, $1=$ never). The difference will be measured on the overall scale.

\section{Secondary outcomes}

Readiness for Interprofessional Learning Scale (RIPLS) is a self-reported assessment of readiness of interprofessional learning [25]. We will use the Danish version of

Table 3 Board illustration

\begin{tabular}{|c|c|c|c|c|c|}
\hline \multirow[t]{2}{*}{$\begin{array}{l}\text { Important } \\
\text { facts: } \\
\text { This we } \\
\text { know }\end{array}$} & $\begin{array}{l}\text { Problems: } \\
\text { This we are not satisfied } \\
\text { with }\end{array}$ & Possible explanations: & $\begin{array}{l}\text { Additional information } \\
\text { required: }\end{array}$ & $\begin{array}{l}\text { Suggestions for procedures, treatment, } \\
\text { etc.: }\end{array}$ & $\begin{array}{l}\text { Study } \\
\text { questions: }\end{array}$ \\
\hline & & $\begin{array}{l}\text { Prognosis if nothing is } \\
\text { done: }\end{array}$ & & $\begin{array}{l}\text { Anticipated effect of measures and } \\
\text { procedures: }\end{array}$ & \\
\hline
\end{tabular}


Table 4 Tentative programme for intervention and control session with quiz and evaluation

\begin{tabular}{lll}
\hline Programme for case-based learning session & \\
\hline Start and stop & Lecture and didactics & $\begin{array}{l}\text { Quiz and } \\
\text { evaluation }\end{array}$ \\
\hline 8:00-8:30 & Welcome and introduction & Multiple-choice quiz \\
$\begin{array}{l}\text { 8:30-10:30 } \\
\text { (with one break) }\end{array}$ & Case-based learning & \\
10:30-11:15 & Recap of relevant guidelines & Multiple-choice quiz \\
11:15-11:30 & End of lecture & Course evaluation \\
\hline
\end{tabular}

RIPLS with four subscales and 29 items distributed on a 5 -point Likert scale, $5=$ strongly agree, $4=$ agree, $3=$ neutral, $2=$ disagree, $1=$ strongly disagree). Items 10,11 and 12 should be reversely coded [26]. The difference will be measured on the overall scale.

Also, a secondary outcome, Safety and Attitude Questionnaire (SAQ) is a self-reported assessment of attitude towards patient safety with 60 items to be rated on a 5point Likert scale, $5=$ Agree strongly, $4=$ Agree slightly, $3=$ Neutral, $2=$ Disagree slightly, $1=$ Disagree strongly). Items two and 11 are negatively worded [23,27]. We will use the Danish version of SAQ [23].

The final secondary outcome is difference in knowledge evaluated using MCQ; evaluation of participants' attitudes about the CBL sessions; qualitative content analysis on interactions between healthcare professionals during the CBL sessions.

\section{Data collection}

This study is ongoing with recruitment starting in September 2019; intervention begins on February 25th to April 1st, 2020. Data collection ends approximately August 2020.

Figure 3 and Table 6 lists timepoint of measurement and collection of outcomes.

\section{Sample size}

Data on the effectiveness of interprofessional education for making the sample size calculation are sparse [21, 28-30].
We have chosen to calculate the required sample size based on previous interprofessional cluster randomised studies [21, 30].

We assume that the primary outcome will be normally distributed with a standard deviation of 20 points [30]. Using a t-test to compare the means in the experimental and the control group and assuming a mean difference of 12 [30], a power of $80 \%$ and a significance level of $5 \%$, we need 45 participants in each group.

\section{Sample size estimation adjusted for clustering}

Observations on participants on the same team will be correlated [31], which means the effective sample size will depend on the intraclass correlation coefficient (ICC) [31]. To adjust the sample size, the crude sample size needs to be multiplied by the design effect. The average cluster size is 13 , and we assume the ICC to be 0.05 .

Design effect $=1+($ cluster size -1$) \mathrm{x}$ ICC $\rightarrow$ design effect $=1.6$. Accordingly, the sample size will be $45 \times 1.6=$ 72 participants in each arm. With at least 80 participants in each group, there is room for up to $10 \%$ missingness.

\section{Allocation and sequence generation}

Blinded randomisation to ICBL (experimental group) and monoprofessional CBL (control group) will be performed centrally by a computer algorithm. To ensure representation of the smaller professional groups in the experimental groups, they will be randomised separately, before randomising the nurses and doctors. MKTOP and JN will generate the allocation sequence that allocates participants to the sessions by the computer algorithm. MKTOP will subsequently contact and enrols participants, and assign them to the session they were randomly selected to participate in. The healthcare professionals, the educators providing the educational intervention, and the researchers analysing the recordings will not be blinded to the intervention. The allocated intervention group will be blinded for the data managers and statisticians.

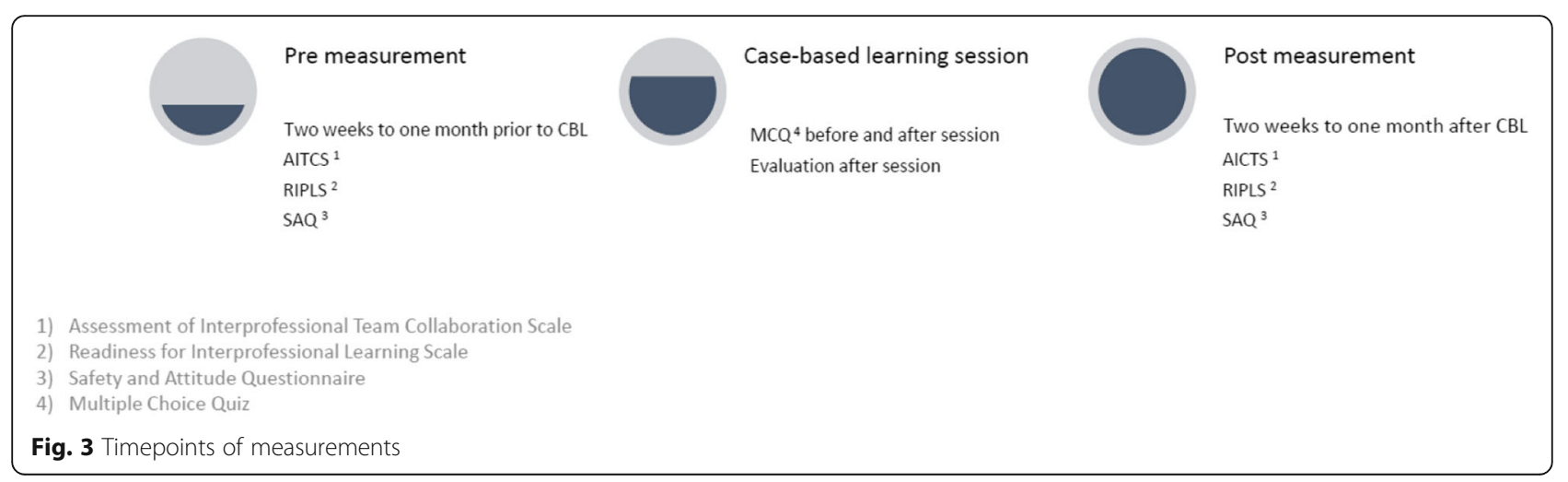


Table 5 Example from MCQ and example from course evaluation

Lesley 11 years old is in the hospital school while waiting to the results on blood samples. With her she has her medication box from home. Suddenly Lesley has a bit of a stomach-ache and would like her pain killer that she can take when she needs it. She just does not remember what it looks like.

Who should the teacher contact:

1. The nurse from the outpatient clinic

2. The doctor from the outpatient clinic

3. Lesley's mom

The professional content of the course was overall (only one mark):

\begin{tabular}{lllll} 
Very poor & Poor & Acceptabel & Good & Very good \\
1 & 2 & 3 & 4 & 5 \\
\hline
\end{tabular}

\section{Statistical methods}

We only expect a small number of missing observations (due to illness, rescheduling, absences) and will assume that these will be missing at random, [32] in which case the linear mixed model is valid, if correctly specified.

For all outcomes, the group means in the experimental and the control group postintervention will be compared, adjusting for the preintervention scores using a linear mixed model that includes the postintervention as outcomes, assuming the group means at baseline to be equal due to randomisation (a constrained linear mixed model [33]). Analyses will be performed unadjusted and adjusted for sex, age, profession and years of work.

\section{Data handling and record keeping}

Each participant will be registered with an individual trial number known only to the $\mathrm{PhD}$ student designing the trial. The study is blinded to all other investigators and management. Participant attendance in the CBL session and completion of their questionnaires will be kept track of. Data on demography and results from questionnaires will be stored in REDCap. The MCQ hardcopies will be archived under the same unique trial number and stored in a locked cabinet at Rigshospitalet.

\section{Quality control and quality assurance}

The trial will be monitored internally only.

\section{Ethics and dissemination}

Participants will be exclusively healthcare professionals or professionals trained to work with children and adolescents with cancer. No patients will be involved in the trial.

\section{Risk and benefits}

There is no anticipation of harm or risk; however, some potential stress, such as fear of exposing one's own lack of knowledge to colleagues may occur. The departments involved in the trial have a well-established system to provide psychological help to staff involved in emergencies, and this system can be activated if trial participants unexpectedly require psychological support.

\section{Ethical considerations}

The trial will comply with the General Data Protection Regulation. Relevant approval by the Danish Data Protection Agency has been obtained. The trial is exempt from approval by the National Committee on Health Ethics Research (http://en.nvk.dk/how-to-notify/whatto-notify). The trial is registered at ClinicalTrials.gov.

Participants will be assured that their personal data, data on questionnaires and audio recordings will remain anonymous during analysis and reporting. The participants will be asked to respect the confidentiality of their observations about colleagues' participation in the CBL session.

\section{Publication plan}

The study will adhere to the International Committee of Medical Journal Editor's guidelines on authorship.

Table 6 Collection of outcomes

\begin{tabular}{|c|c|c|c|c|c|}
\hline Schedule & 2-4 months before intervention & $\begin{array}{l}2 \text { months before } \\
\text { intervention }\end{array}$ & $\begin{array}{l}\text { 1-2 months before } \\
\text { intervention }\end{array}$ & $\begin{array}{l}\text { Intervention: Case-based } \\
\text { learning }\end{array}$ & $\begin{array}{l}1-3 \text { months } \\
\text { after } \\
\text { intervention }\end{array}$ \\
\hline $\begin{array}{l}\text { Information } \\
\text { for all staff }\end{array}$ & $\begin{array}{l}\text { Oral information at meetings } \\
\text { and conferences about case- } \\
\text { based learning }\end{array}$ & $\begin{array}{l}\text { Written and oral } \\
\text { information by individual } \\
\text { email to all staff }\end{array}$ & $\begin{array}{l}\text { Oral information for } \\
\text { participants interested in } \\
\text { randomisation }\end{array}$ & & \\
\hline $\begin{array}{l}\text { Trial } \\
\text { participants }\end{array}$ & & & $\begin{array}{l}\text { Participants will be } \\
\text { included consecutively. }\end{array}$ & & \\
\hline $\begin{array}{l}\text { Trial } \\
\text { participants }\end{array}$ & & & $\begin{array}{l}\text { Pre AITCS } \\
\text { Pre RIPLS } \\
\text { Pre SAQ }\end{array}$ & $\begin{array}{l}\text { MCQ on gastrointestinal } \\
\text { side effects } \\
\text { Course evaluation }\end{array}$ & $\begin{array}{l}\text { Post AITCS } \\
\text { Post RIPLS } \\
\text { Post SAQ }\end{array}$ \\
\hline $\begin{array}{l}\text { Data } \\
\text { collection on } \\
\text { participants }\end{array}$ & & & $\begin{array}{l}\text { Demographic data: sex, } \\
\text { age, profession and years } \\
\text { of work }\end{array}$ & $\begin{array}{l}\text { Observations of interaction: } \\
\text { who speaks, when and } \\
\text { about what }\end{array}$ & \\
\hline
\end{tabular}

AITCS Assessment of Interprofessional Team Collaboration Scale, MCQ multiple-choice quiz, RIPLS Readiness for Interprofessional Learning Survey, SAQ Safety Attitude Questionnaire 
This randomised trial is part of Martha Krogh Topperzer's $\mathrm{PhD}$ project entitled: "Interprofessional education in childhood cancer". In addition to a publication resulting from this trial, other publications $[8,9]$ will comprise her $\mathrm{PhD}$ dissertation.

\section{Publications planned Design articles}

"Interprofessional versus monoprofessional casebased learning in childhood cancer and the effect on healthcare professionals' interprofessional attitudes and knowledge: study protocol for a randomised controlled trial".

"Interprofessional case-based learning improves healthcare professionals' interprofessional attitudes in childhood cancer: a randomised controlled trial".

"Intra-professional interactions: findings from interprofessional case-based learning in childhood cancer".

All results from the trial (negative, positive and inconclusive) will be published in a scientific journal or, alternatively, in a report and online.

Juliane Marie Centre for children, women and reproduction, Rigshospitalet, University of Copenhagen, Denmark is responsible for the intervention.

\section{Discussion}

To our knowledge, this is the first randomised trial investigating the effect of interprofessional versus monoprofessional CBL on healthcare professionals' interprofessional attitudes.

This study will provide insight into the differences between interprofessional and monoprofessional CBL and how it affects the healthcare professionals' interprofessional collaboration and attitudes. Moreover, this study will contribute data on teaching methods for interprofessional teamwork skills, as the evidence in this area is sparse [34].

A potential limitation of this trial is that it is a singlecentre trial that includes only a moderate number of participants. There is a risk of contamination among participants as some of the healthcare professionals work together and can influence each other across randomised groups. At the CBL session, participants will be told not to speak about the intervention with their colleagues as doing so may interfere with the trial results.

Another limitation is that there are no clinical outcomes such as decreased scores of gastrointestinal side effects because the primary outcome is a test of healthcare professionals' attitudes. Provision of knowledge does not necessarily result in practice change [35]. Not only does practice change happen slowly, but the healthcare system is inherently complex, with multiple confounding factors such as the rapid turnover of healthcare professionals, maternity leave and postgraduate education for doctors, for example [36].

Interventions directed at the behaviour of healthcare professionals are categorised as complex because they consist of various interconnecting components [37]. The causality of health education interventions is multifactorial, making it difficult to reproduce exactly. Designing a framework for evaluating complex interventions may represent a relevant step in ensuring the continued implementation of an interprofessional curriculum.

\section{Supplementary Information}

The online version contains supplementary material available at https://doi. org/10.1186/s12913-020-05980-2.

\section{Additional file 1.}

Abbreviations

AITCS: Assessment of Interprofessional Team Collaboration Scale; CBL: Casebased learning; ICC: Intraclass correlation coefficient; ICBL: Interprofessional case-based learning; MCQ: Multiple-choice quiz; RIPLS: Readiness for Interprofessional Learning Survey; SAQ: Safety Attitude Questionnaire

\section{Acknowledgements}

We wish to thank the head of clinical services, Karen Vitting Andersen; head of department Lisa Hjalgrim; and head nurses Marianne Madsen and Pernille Roland for making this intervention possible. We would also like to thank managers Maria Bennedsen, Karen Berget, Lone Stisen and Lone Sparrevohn Mørck for prioritising the participation of their health professional employees in this intervention. Thank you to Mads Skipper for discussing the objective of this intervention.

\section{Authors' contributions}

MKTOP and JLS created the idea for the trial. MKTOP, MHH, HBL and JLS designed and planned the trial and intervention. MKTOP, MHH, HBL, BL, KS and JLS made contributions to the design, practical issues and logistics of the trial. MKTOP, JN, SR and JLS contributed to the sample size estimation and detailed designing and execution of the randomisation process. LIR, PP and LAJ contributed with critical feedback on writing the case and MCQ. MKTOP wrote the draft manuscript. All authors (MKTOP, MHH, HBL, SR, JN, $L I R, P P, L A J, B L, K S$ and $J L S$ ) provided critical review of this protocol and approved the final manuscript.

\section{Funding}

This work is part of Childhood Oncology Network Targeting Research, Organisation \& Life expectancy (CONTROL) and supported by the Danish Childhood Cancer Foundation (2015-73).

The Danish Childhood Cancer Foundation has no role in the design of the study, nor in the collection, analysis, or interpretation of data collected. Ultimately the foundation has no role in writing the manuscript. The study protocol has not undergone peer-review by the funding body.

\section{Availability of data and materials}

All data generated and analysed during this study will be available in subsequently published articles. This study has not been submitted to or published at any other journal.

\section{Ethics approval and consent to participate}

This trial is fully approved by the Data Protection Agency: P-2019-637. The trial is exempt from approval by the National Committee on Health Ethics Research (http://en.nvk.dk/how-to-notify/what-to-notify) as surveys using 
questionnaires and interviews that do not involve human biological material (section 14 (2) of the Committee Act) research projects, not including biological material do not need the approval of the research ethics committee system and has received an exemption number: $\mathrm{H}-19087506$.

The trial is registered at ClinicalTrials.gov NCT04204109.

Participants will be informed that they consent to participate when answering the REDcap questionnaires. Participants will be informed that they can withdraw their consent and discontinue their participation at any time.

\section{Consent for publication}

Not applicable.

\section{Competing interests}

The authors declare that they have no competing interests.

\section{Author details}

1Paediatric Oncology Research Laboratory, Department of Paediatrics and Adolescent Medicine, Rigshospitalet, University of Copenhagen, Blegdamsvej 9, 2100 Copenhagen, Denmark. ²Department of Paediatrics and Adolescent Medicine, Rigshospitalet, University of Copenhagen, Blegdamsvej 9, 2100 Copenhagen, Denmark. ${ }^{3}$ Section of Biostatistics, Faculty of Health Sciences, University of Copenhagen, Øster Farimagsgade 5, 1014 Copenhagen,

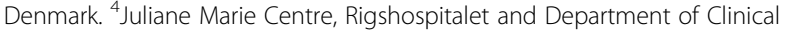
Medicine, University of Copenhagen, Copenhagen, Denmark.

\section{Received: 13 April 2020 Accepted: 26 November 2020}

\section{Published online: 04 December 2020}

\section{References}

1. Anderson RA, Marshall NS. The importance of the pediatric oncologist-nurse partnership in the delivery of total care in pediatric oncology. Med Pediatr Oncol. 2000;34(4):263-4.

2. Reaman GH. Pediatric cancer research from past successes through collaboration to future transdisciplinary research. J Pediatr Oncol Nurs. 2004; 21(3):123-7.

3. Christiansen HL, Bingen K, Hoag JA, Karst JS, Velázquez-Martin B, Barakat LP. Providing children and adolescents opportunities for social interaction as a standard of Care in Pediatric Oncology. Pediatr Blood Cancer. 2015;62:S674-99.

4. Gatta G, Botta L, Rossi S, Aareleid T, Bielska-Lasota M, Clavel J, Dimitrova N, Jakab Z, Kaatsch P, Lacour B, et al. Childhood cancer survival in Europe 1999-2007: results of EUROCARE-5--a population-based study. Lancet Oncol. 2014;15(1):35-47.

5. Schmiegelow K, Attarbaschi A, Barzilai S, Escherich G, Frandsen TL, Halsey C, Hough R, Jeha S, Kato M, Liang DC, et al. Consensus definitions of 14 severe acute toxic effects for childhood lymphoblastic leukaemia treatment: a Delphi consensus. Lancet Oncol. 2016;17(6):e231-9.

6. Mulrooney DA, Hyun G, Ness KK, Bhakta N, Pui C-H, Ehrhardt MJ, Krull KR, Crom DB, Chemaitilly W, Srivastava DK, et al. The changing burden of longterm health outcomes in survivors of childhood acute lymphoblastic leukaemia: a retrospective analysis of the St Jude lifetime cohort study. Lancet Haematol. 2019;6(6):e306-16.

7. Thomas PA, Kern DE, Hughes MT. Chen BY (eds.): curriculum development for medical education : a six-step approach. Baltimore: Springer Publishing Company; 2016

8. Topperzer MK, Hoffmann M, Roug LI, Larsen HB, Lausen B, Schmiegelow K, Sørensen JL. Unmet need for interprofessional education in paediatric cancer: a scoping review. Support Care Cancer. 2019;27(10):3627-37.

9. Topperzer MK, Thellesen L, Hoffmann M, Larsen HB, Weibel M, Lausen B, Schmiegelow K, Sørensen JL. Establishment of consensus on content and learning objectives for an interprofessional education in childhood cancer: a Delphi survey. BMJ Paediatr Open. 2020;4(1):e000634.

10. Lindqvist S, Duncan A, Shepstone L, Watts F, Pearce S. Case-based learning in cross-professional groups - the development of a pre-registration interprofessional learning programme. J Interprof Care. 2005;19(5):509-20.

11. Kiessling A, Henriksson P. Efficacy of case method learning in general practice for secondary prevention in patients with coronary artery disease: randomised controlled study. BMJ. 2002:325(7369):877-80.

12. Kiessling A, Lewitt M, Henriksson P. Case-based training of evidence-based clinical practice in primary care and decreased mortality in patients with coronary heart disease. Ann Fam Med. 2011;9(3):211-8.
13. Erskine J, Leenders M, Maufette-Leenders L. Teaching with cases, third edition edn: The University of Western Ontario, Canada: Ivey publishing; 200.

14. Thistlethwaite JE, Davies D, Ekeocha S, Kidd JM, MacDougall C, Matthews P, Purkis J, Clay D. The effectiveness of case-based learning in health professional education. A BEME systematic review: BEME guide no. 23. Med Teach. 2012;34(6):e421-44.

15. O'Brien BC, Patel SR, Pearson M, Eastburn AP, Earnest GE, Strewler A, Gager K, Manuel JK, Dulay M, Bachhuber MR, et al. Twelve tips for delivering successful interprofessional case conferences. Med Teach. 2017;39(12):1214-20.

16. Harris PA, Taylor R, Thielke R, Payne J, Gonzalez N, Conde JG. Research electronic data capture (REDCap) - a metadata-driven methodology and workflow process for providing translational research informatics support. J Biomed Inform. 2009:42(2):377-81.

17. Boynton PM, Greenhalgh T. Hands-on guide to questionnaire research: selecting, designing, and developing your questionnaire. BMJ. 2004; 328(7451):1312-5.

18. Sorensen JL, Thellesen L, Strandbygaard J, Svendsen KD, Christensen KB, Johansen M, Langhoff-Roos P, Ekelund K, Ottesen B, Van Der Vleuten C. Development of knowledge tests for multi-disciplinary emergency training: a review and an example. Acta Anaesthesiol Scand. 2015;59(1):123-33.

19. InCase [https://www.rigshospitalet.dk/afdelinger-og-klinikker/julianemarie/ enhed-for-simulation/for-fagfolk/simulationsbaseret-forskning-og-traening/ Sider/incase-interprofessional-cancer-education.aspx].

20. Reeves S, Kuper A, Hodges BD. Qualitative research methodologies: ethnography. BMJ. 2008;337:a1020.

21. Marcussen M, Nørgaard B, Borgnakke K, Arnfred S. Interprofessional clinical training in mental health improves students' readiness for interprofessional collaboration: a non-randomised intervention study. BMC Med Educ. 2019; 19(1):27.

22. Hellman T, Jensen I, Orchard C, Bergström G. Preliminary testing of the Swedish version of the assessment of Interprofessional team collaboration scale (AITCS-S). J Interprof Care. 2016;30(4):499-504.

23. Kristensen SSS, Bartels P, Mainz J, Christensen KB. Adaption and validation of the safety attitudes questionnaire for the Danish hospital setting. Clin Epidemiol. 2015;7:149-60.

24. Orchard CA, King GA, Khalili H, Bezzina MB. Assessment of Interprofessional team collaboration scale (AITCS): development and testing of the instrument. J Contin Educ Heal Prof. 2012;32(1):58-67.

25. McFadyen AK, Webster V, Strachan K, Figgins E, Brown H, McKechnie J. The readiness for interprofessional learning scale: a possible more stable subscale model for the original version of RIPLS. J Interprof Care. 2005;19(6): 595-603.

26. Nørgaard B, Draborg E, Sørensen J. Adaptation and reliability of the readiness for inter professional learning scale in a Danish student and health professional setting. BMC Med Educ. 2016;16:60.

27. Sexton JB, Helmreich RL, Neilands TB, Rowan K, Vella K, Boyden J, Roberts PR, Thomas EJ. The safety attitudes questionnaire: psychometric properties, benchmarking data, and emerging research. BMC Health Serv Res. 2006;6:44.

28. Reeves S, Perrier L, Goldman J, Freeth D, Zwarenstein M. Interprofessional education: effects on professional practice and healthcare outcomes (update). Cochrane Database Syst Rev. 2013;3:Cd002213.

29. Reeves S, Pelone F, Harrison R, Goldman J, Zwarenstein M. Interprofessional collaboration to improve professional practice and healthcare outcomes. Cochrane Database Syst Rev. 2017;6:Cd000072.

30. Grymonpre R, Bowman S, Rippin-Sisler C, Klaasen K, Bapuji SB, Norrie O, Metge C. Every team needs a coach: training for interprofessional clinical placements. J Interprof Care. 2016;30(5):559-66.

31. Campbell MK, Piaggio G, Elbourne DR, Altman DG. Consort 2010 statement: extension to cluster randomised trials. BMJ. 2012;345:e5661.

32. Schafer J. Analysis of incomplete multivariate data. New York: Chapman and Hall/CRC; 1997.

33. Coffman CJ, Edelman D, Woolson RF. To condition or not condition? Analysing 'change' in longitudinal randomised controlled trials. BMJ Open. 2016;6(12):-e013096.

34. Fox L, Onders R, Hermansen-Kobulnicky CJ, Nguyen TN, Myran L, Linn B, Hornecker J. Teaching interprofessional teamwork skills to health professional students: a scoping review. J Interprof Care. 2018;32(2):127-35.

35. Patterson M, Rick J, Wood S, Carroll C, Balain S, Booth A. Systematic review of the links between human resource management practices and performance. Health Technol Assess. 2010;14(51):1-334 iv. 
36. Thistlethwaite J. Interprofessional education: 50 years and counting. Med Educ. 2016;50(11):1082-6.

37. Campbell NCME, Darbyshire J, Emery J, Farmer A, Griffiths F, et al. Designing and evaluating complex interventions to improve health care. Br Med J. 2007;334(7591):7455

\section{Publisher's Note}

Springer Nature remains neutral with regard to jurisdictional claims in published maps and institutional affiliations.

Ready to submit your research? Choose BMC and benefit from:

- fast, convenient online submission

- thorough peer review by experienced researchers in your field

- rapid publication on acceptance

- support for research data, including large and complex data types

- gold Open Access which fosters wider collaboration and increased citations

- maximum visibility for your research: over $100 \mathrm{M}$ website views per year

At BMC, research is always in progress. 